European Journal of STEM Education, 1:3 (2016), 57

ISSN: $2468-4368$

\title{
GeoloGIS-BH: An Information System for Using the Built Heritage for Geological Teaching
}

C Alves ${ }^{1 *}$, Vitor Ribeiro ${ }^{1}$, Marta Cunha ${ }^{1}$, Paula Pereira ${ }^{1}$, Cláudia Pinto ${ }^{1}$

${ }^{1}$ University of Minho, PORTUGAL

*Corresponding Author: casaix@dct.uminho.pt

Citation: Alves, C., Ribeiro, V., Cunha, M., Pereira, P. and Pinto, C. (2016) GeoloGIS-BH: An Information System for Using the Built Heritage for Geological Teaching, European Journal of STEM Education, 1:3 (2016), 57.

doi: http://dx.doi.org/10.20897/lectito.201657

Received: April 1, 2016; Accepted: May 30, 2016; Published: August 8, 2016

\begin{abstract}
There are examples of using stones of the cultural heritage for teaching purposes. Information systems have found several potential uses in the promotion and preservation of cultural heritage. In this paper is considered the conceptual framework of an information system concerning features of geological interest (FGI) in the built heritage (without any consideration in terms of its software implementation). This FGI concept is used here in a very wide sense to encompass characteristics of geological materials that can be recognized with the naked eye and analogies of geological processes in the built environment. Two perspectives are considered for information organization: occurrences of FGIs in the built heritage (more suitable for Earth Sciences teaching) and FGIs as components of built heritage elements (more suitable for humanities teaching). The main issue that arises from the ensuing discussion was found to be the findability of a given FGI, depending on its visual contrast and the characteristics of the built heritage element. It is argued that, in this way, geological concepts can contribute to the promotion and conservation of the built heritage.
\end{abstract}

Keywords: built environment, feature of geological interest, Earth Sciences teaching, information systems, spatial referencing

\section{INTRODUCTION}

Stones in buildings can be important elements for geological illustration (some examples of this can be seen in Williams 2009, Williams 2012, Pereira \& Marker 2016) and its weathering can also be used as it relates to environmental conditions (Perez-Monserrat et al., 2016). There are several examples of using GIS for preparing and managing teaching and touristic activities in relation to cultural elements (Balestro et al. 2015; Hoerig et al. 2015; Sheng \& Tang, 2015).

However, we were unable to find any previous example similar to the perspective considered in the present paper: the use of spatial-based information systems for promoting building stone use in education (formal and informal - this last one being similar to tourism promotion).

We propose that this distinction is a non trivial one as there will be specific problems related to it that, hopefully, we will be able to show here. A brief abstract in Portuguese and the corresponding presentation also in Portuguese in relation to the specific subject of this paper have already been presented (Alves et al. 2016). 


\section{THE GEOLOGIS CONCEPTUAL FRAMEWORK}

The basic principles of the GeoloGIS (originally SIGeolog in Portuguese) conceptual framework have already been presented in Portuguese (Cunha et al. 2016). Hence, we will present here a brief synthesis of it considering the features that are relevant to this paper. However, we will not consider any question in relation to the software implementation of the system. The GeoloGIS is presented as a system made by sets that we will call sections (corresponding to geologic themes such as Petrology, Stratigraphy, etc.) with diverse kind of objects and that (at least at this conceptual level) can be seen as an extended version of the classical "layer" concept without limitations in terms of the characteristics of the objects, which, in any given section can be of matrix or vector type, points, lines, areas, surfaces, volumes and even objects of a higher dimension (objects of n-dimension, in general).

One of the premises of this structure is that it must be flexible and allow its information to be re-organized for new applications. We will illustrate this with the extension of the section of geologic materials to the promotion of the geological features of the cultural heritage.

Each object on a given section will have a matrix of informations in relation to diverse characteristics. This informations can be of diverse types such as nominal, ordinal, numerical and even objects which can have informations of the types mentioned, defining an open system (similar to the folder system in the popular operating systems such as Windows or Ubuntu). The system sections should be able to share objects and their informations. The system must be able (this is critical for the present work) to create new sections by copy, redistribution or synthesis of existing informations, or by addition of new ones.

The extension of the GeolGIS framework to the geological component of the built heritage will be discussed in the next section.

\section{TWO PERSPECTIVES ON DATA ORGANIZATION}

The GeoloGIS-BH will be discussed as a collection (that could be used autonomously) prepared from the collections of the basic GeoloGIS, such as Petrology, Geological Resources and Engineering Geology. Two perspectives of data organization will be considered (Figure 1), considering the dual purpose of showing, on the one hand, to science students examples of the application of their study objects and, on the other hand, showing humanities students characteristics of the constituents of their objects (these two perspectives can constitute different applications that could be obtained from the same basis following the procedures presented in the previous section). The first one (more suited to a science-minded public, specially Earth Sciences students but also for public with interest in biology, physics, chemistry) sees the built heritage elements as occurrences of examples of materials, their characteristics and transformations as well as their applications, what will be referred generically as features of geological interest (FGI); the objects will be the FGI; the built heritage places will be part of the

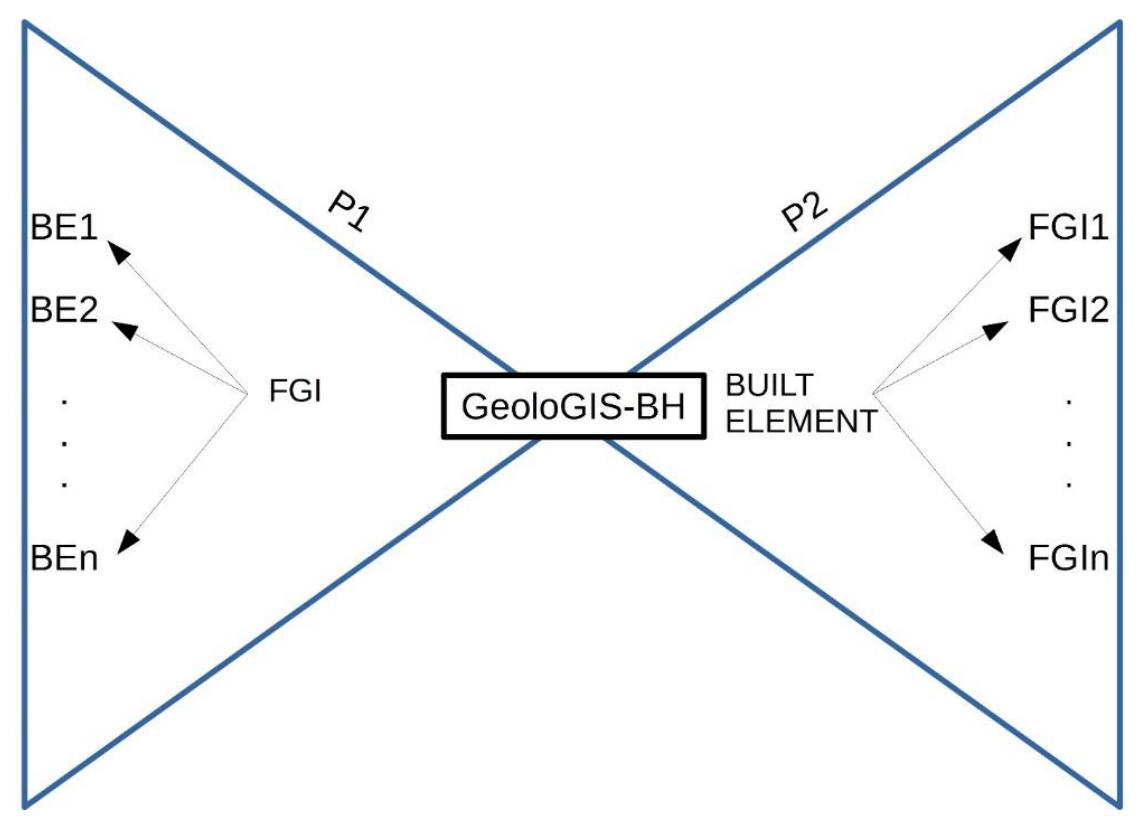

Figure 1. A visual comparison of the two perspectives proposed for the GeoloGIS-BH: in P1 (left side), the feature of geological interest (FGI) is the centre of attention and are registered the built elements where it can be found (BE1 ... BEn) while in P2 (right side), the built element is the centre of attention and are registered the features of geological interest that are present on it (FGI1, .., FGIn). 


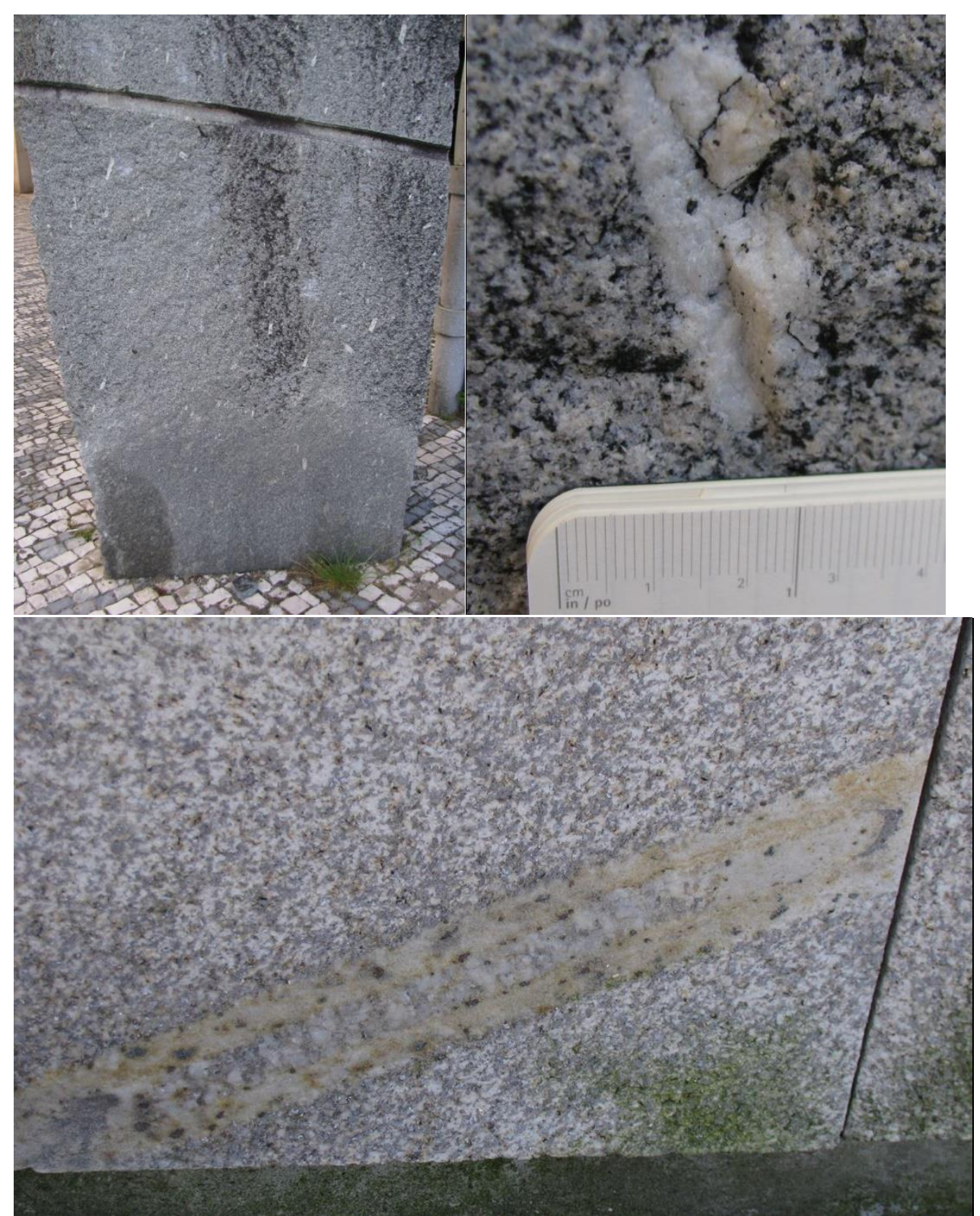

Figure 2. Examples of features of geological interest (FGIs) in built environment: biotitic porphyric granite (upper left hand); twinning on feldspar (upper right hand); aplite-pegmatite textures in a veinlet of a two-mica granite (lower image).

information on those FGIs. In the second perspective (more suited for a more historical and architectural orientated public), the built heritage elements are the objects and the geological materials are seen as informations of these objects.

In the first perspective, as already said above, the main focus will be on the FGIs that can illustrate (and be teaching tools) for rock types, textural and structural features, weathering transformations and other geological features. The cultural heritage places will serve the spatial location of these illustration/teaching FGIs. The FGI concept is used here in a very wide sense that includes features in geologic materials that can be recognized in the field with the naked eye as well as analogies of geologically interesting processes that develop in the built environment without intervention of humans (both in geological materials or in materials prepared from geologic raw materials). For example, and following the illustration of already existing applications on other areas such as hotel search, one can occurrences for places in a given location (administrative unit) or in a given radius of a reference point that show volcanic rocks, tourmaline in veins, weathered granites, carbonate rock erosion or "mineral"-like neoformations. In Figure 2 are presented some examples of the use of built elements for showing geological features such as mineralogical and textural features: in Figure 2 (upper left image) is shown a porphyric biotitic granite, in Figure 2 (upper right image) is shown an example of twinning in feldspars and in Figure 2 (lower image) is shown the occurrence of aplitic-pegmatite veinlet in a two-mica granite. The built environment 


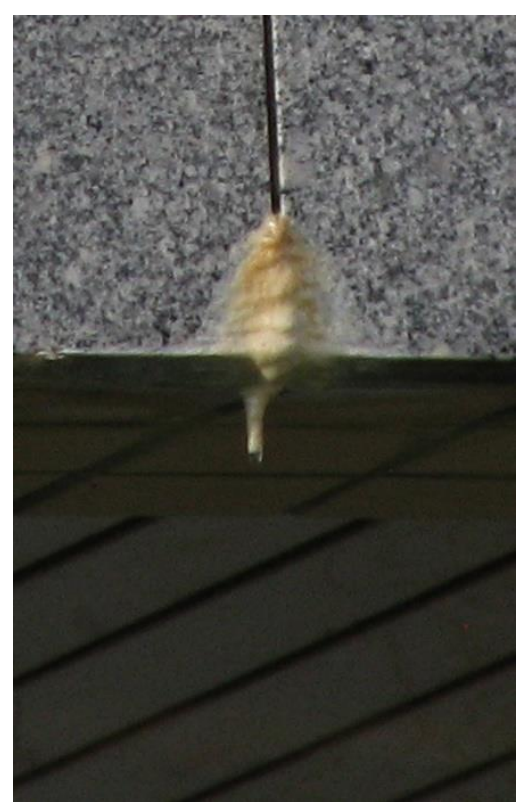

Figure 3. Example of calcium carbonate neoformation with stalactite-like structure on a granite slab (if you look closely you might be able to see on the lower tip of the "stalactite" a drop of the solutions that are forming it).

can also be used to show geologic substances (and their features) not available locally, e.g. carbonate rocks on granite locations (as will be illustrated in the next section).

However, care must be taken in relation to this use of features in the built heritage as they occur outside their original geological context constituting an extreme case of censored observation. It can be argued that all geological observations are censored observations (limited to the available outcrops, boreholes or indirect geophysical and geochemical information) but in the case of the materials in the built heritage knowledge improvement is severely limited. For example, one frequently does not even know whether adjacent blocks came from the same quarry and there could be human interventions at different times.

The question of crystalline substances neoformations in the built environment might be worthy on some further comments as it can be a polemic point (see Alves, 2013a). According to the International Mineralogical Association (IMA) recommendations (Nickel, 1995), inorganic crystalline substances that result from interaction of human materials with the weather elements are not considered minerals since this can create a diversity of substances that does not correspond to the natural environment. However, neoformations in the built environment generally are also found in the natural environment (Alves, 2013a,b) and since there were not made purposely by humans we think it will not be against the spirit of these IMA recommendations to consider the neoformations of the built environment as minerals. A possible exception to this could be the weathering products of metals or advanced (non-traditional) materials. However, these products are not totally devoid of interest for the geological sciences as they can suggest the conditions where new minerals could be found.

The neoformations of the built environment can be useful to illustrate morphological, textural and, depending on the available laboratory conditions, chemical and internal structure features. For example, a common feature on the built environment are occurrences of calcium carbonate deposits with a calcite structure that in some places (depending on the spatial patterns of the solutions circulation) can produce structures similar to stalactites (as in Figure 3) and stalagmites. It is possible, and the first author of this paper has performed that experience with students, to perform simple field tests such as $\mathrm{pH}$ paper tests of the solutions, showing their alkaline character (see illustration in Alves and Sanjurjo-Sánchez 2015) or acid reaction of the carbonate deposits. It is also possible to collect samples from the carbonate deposits for optical microscopy (e.g. to show deposition textures), X-ray difractograms or scanning electron microscopy studies. Another experience concerns the sampling of solutions from the places where these substances are being deposited for simple experiences such as laboratory crystallization by simple air drying (the crystallization products can be studied with simple optical instruments or can be subject to more advanced laboratory studies).

However, the genetic context of the neoformations deserves some careful framing as there are some substances that occur in context very different from the natural one, as is the, rather common, case of gypsum crusts on granites (Sanjurjo-Sánchez et al. 2009). There are also situations where while there are great similarities in terms of texture and structure, the chemical basis of the genesis process present significant differences, as in the case of the carbonate deposits (see Liu \& He, 1998). 


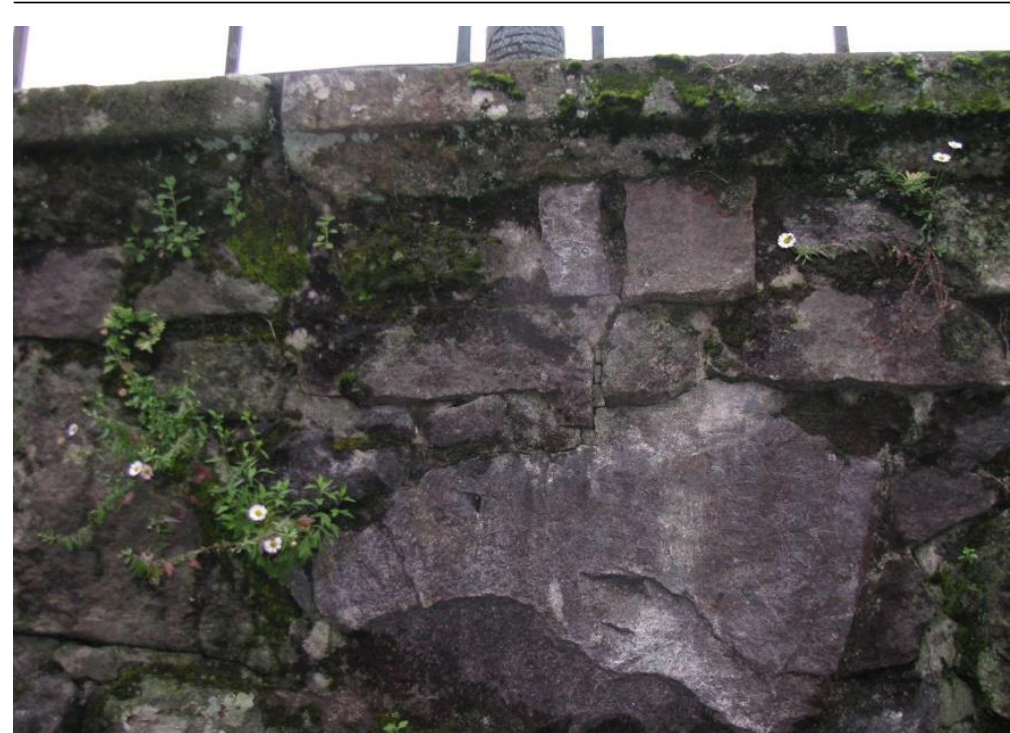

Figure 4. Illustrative image of relations between substrate and biological colonization with lichens and moss on the stones and plants in the joints between the wall stones.

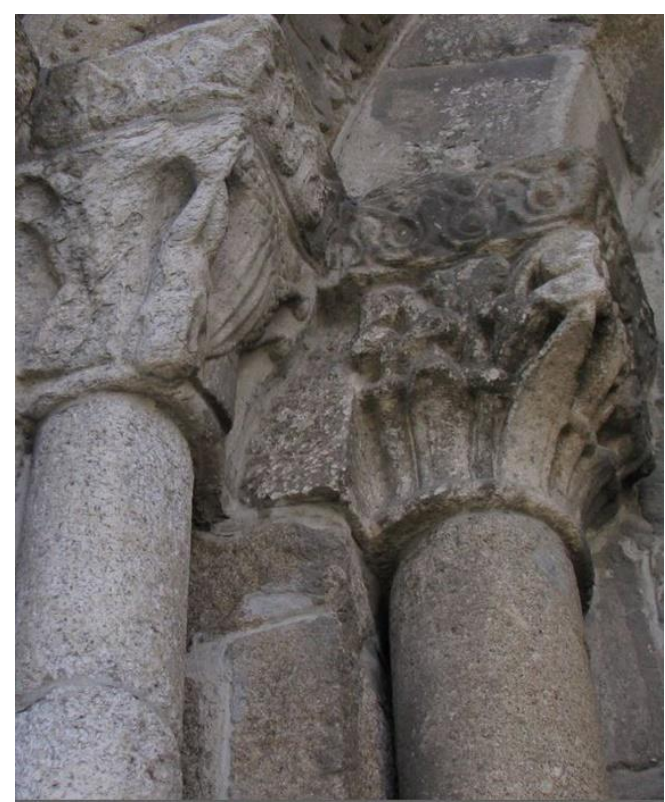

Figure 5. Image of two granite types on columns of a portal in a monument of Braga (NW Portugal): the darkishbrownish one on the right is similar to the local granite while the lighter one on the left is similar to certain facies from surrounding regions.

The built elements can also contribute to the teaching of relations between substrates and biological activity as is illustrated in Figure 4 where the development of biological colonization shows patterns associated with the type of substrate with lichens and moss on the stones and plants on the spaces between the stones.

This first perspective might include historical and architectural (and engineering) information on the places where the geologic materials are applied as they relate to the geological context and the characteristics of the materials but these components will be dominant in the second perspective. It can be considered that this second perspective will be stretching too far the concept of the GeoloGIS given the dominance of non-geological information but we argue that the information of the basic GeoloGIS on geologic materials can be organized to be integrated in this second perspective, constituting an example of collaboration between the hard sciences, such as Geology, and the humanities. In this second perspective the level of detail for the FGI will be generally lower and findability will be higher since usually the reference is to an architectural element with FGIs such as a stone or a stone group of a rock type or diverse rock types as in Figure 5 where it is intended to show two different types of granites on a portal (one of which is local while the other not). However, there could be more specialized situations (for example for post-graduate students of the humanities areas), where it is intended to show FGIs such as a given mineral occurrence that supports a certain hypothesis concerning the source of a given material or FGIs that can be used for dating heritage elements (Sanjurjo-Sánchez, 2016). 


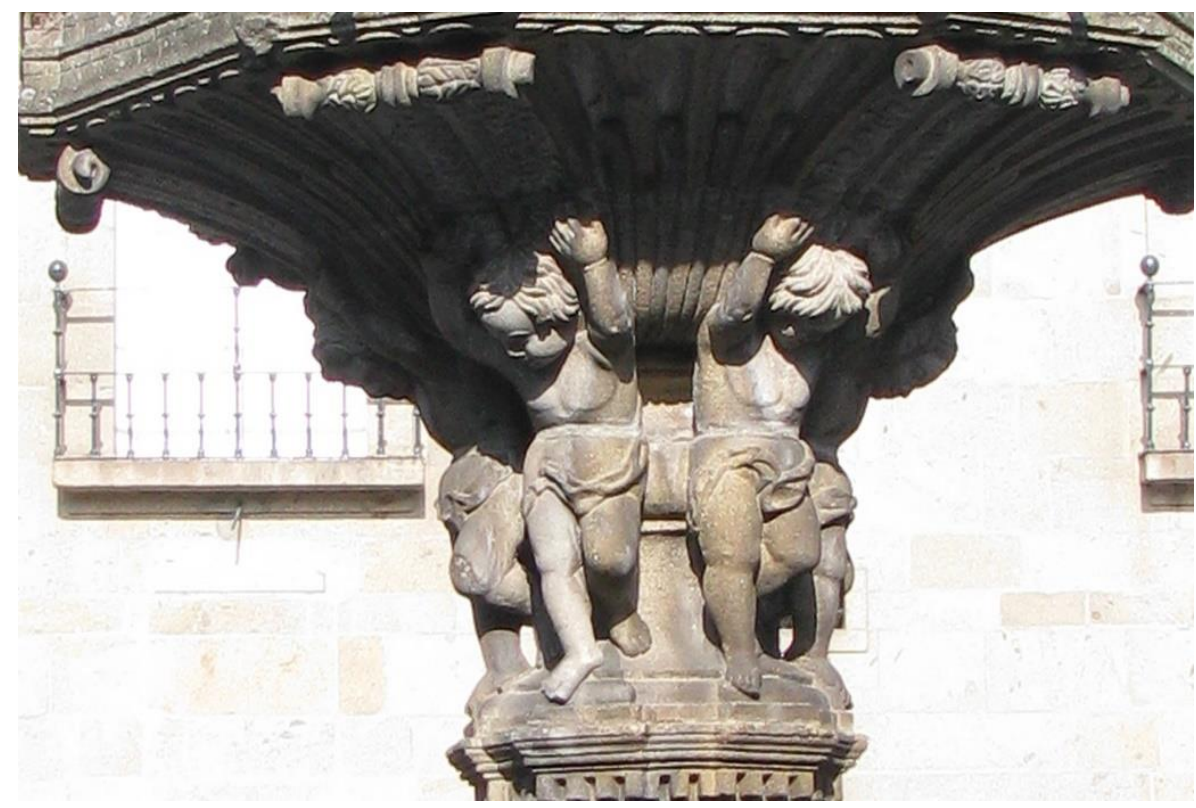

Figure 6. Image from a granite fountain (location of specific details will be an excruciating challenge).

\section{FEATURES FINDABILITY}

Besides the software implementation issues, the main problem for this extension of the GeoloGIS will be related to the question of "ambient findability" (Morville 2005), to wit, the development of reference systems to locate the occurrences of the places for observation of the FGIs, especially for the first perspective. Of course the question of the findability of a given FGI will also depend of its visual contrast (resulting from size, colour and texture in relation to the surrounding), as is illustrated in Figure 5 where the granite types have a clear colour contrast that helps their distinction but in the following discussion this question will be ignored (i.e. we will treat the subject of location regardless of visual contrast).

The complexity of this issue will range from the observation of a given rock type on free standing monolithic structures (as illustrated in Figure 2, upper right image) where GPS coordinates and a photograph might be enough (the structure is the FGI). However, findability will markedly decrease in the case of a specific FGI that occurs on a given spot. In the case considered one can add some descriptors like south view, height from ground and horizontal distance from a given side. There are elements (as illustrated on Figure 6) that might be easy to locate (by GPS or by building plan) but due to their geometric round form and irregular distribution of decorative it will almost impossible to define a referencing system for defining the position of more spot-like FGIs (weathered features; rare mineral occurrences). In such situations tools like PhotosynthTM (https://photosynth.net/default.aspx) from Microsoft Corporation can help in the visual location of features.

Our next example concerns the Youth statue (Figure 7) in downtown Porto (NW Portugal); a town located on granite terrains. The statue is on a squared base pedestal whose sides are made of two carbonate rocks types: a low porosity limestone with fossils (as shown in the inset at the low left of Figure 7) and marble. In this case the monument can be located by GPS and the location of specific details can be easily established by geometrical referencing for the stones in a given face of the pedestal (in the case of Figure 7 it is the east side) but it will be harder for the more irregularly disposed stones (and their weathering features) on the water basins at the bottom of the pedestal. 


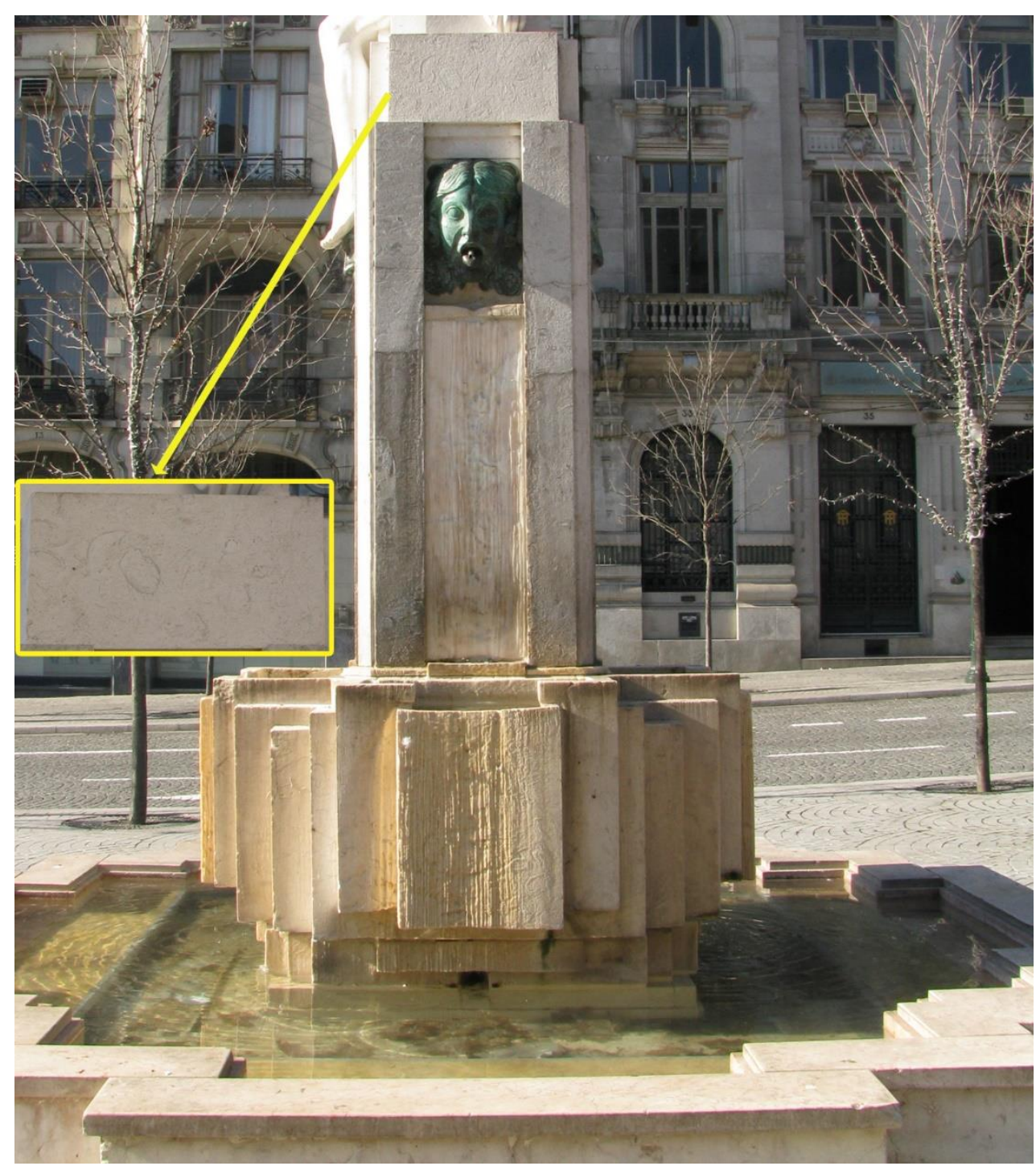

Figure 7. View of the east side of the pedestal of the Youth statue in Porto (NW Portugal - a town located on granite terrains) with inset showing the fossils.

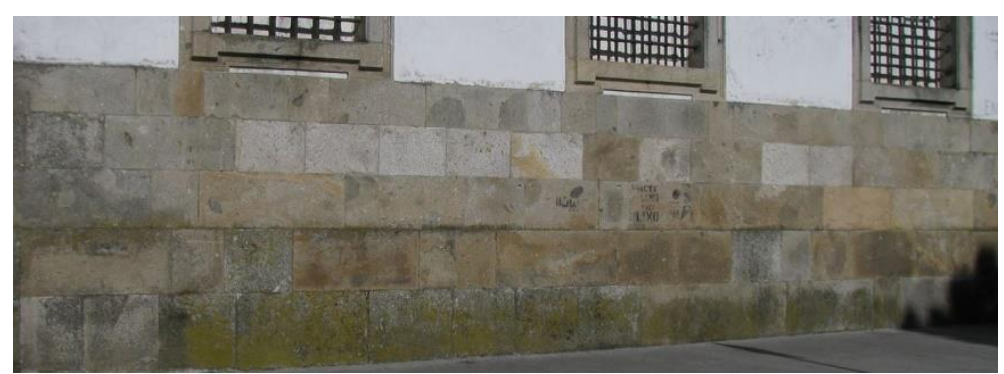

Figure 8. A wall with regular distribution of regular shaped stones (it is possible to define referencing for locating individual stones and individual features inside a given stone).

Regular walls (as in Figure 8) that show diverse types of granitic rocks) made of regular geometrically stones can be also object of precise referencing (due to the geometrical conditions). The wall can be locate by GPS coordinates (or, in this case, by a building plan), and the regular pattern allows to locate each individual stone in the wall (by indicating the line number from upper or lower one and the stone number in that line from either right or left or south or north). The geometry of the stone faces (rectangles) allows locations of smaller FGIs within each stone by using horizontal and vertical distances from reference points (e.g. upper left corner). In this way it is possible to "digitize" the geological features of the wall stones.

Rock aggregates (that can be a teaching tool, either in terms of basic concepts such as rock types or in terms of rock properties) illustrates the issue of referencing: it will be easy to show the use of a rock type (e.g. see pavement in street X) but it might be very difficult (impossible?) to locate a FGI in a specific aggregate particle. 


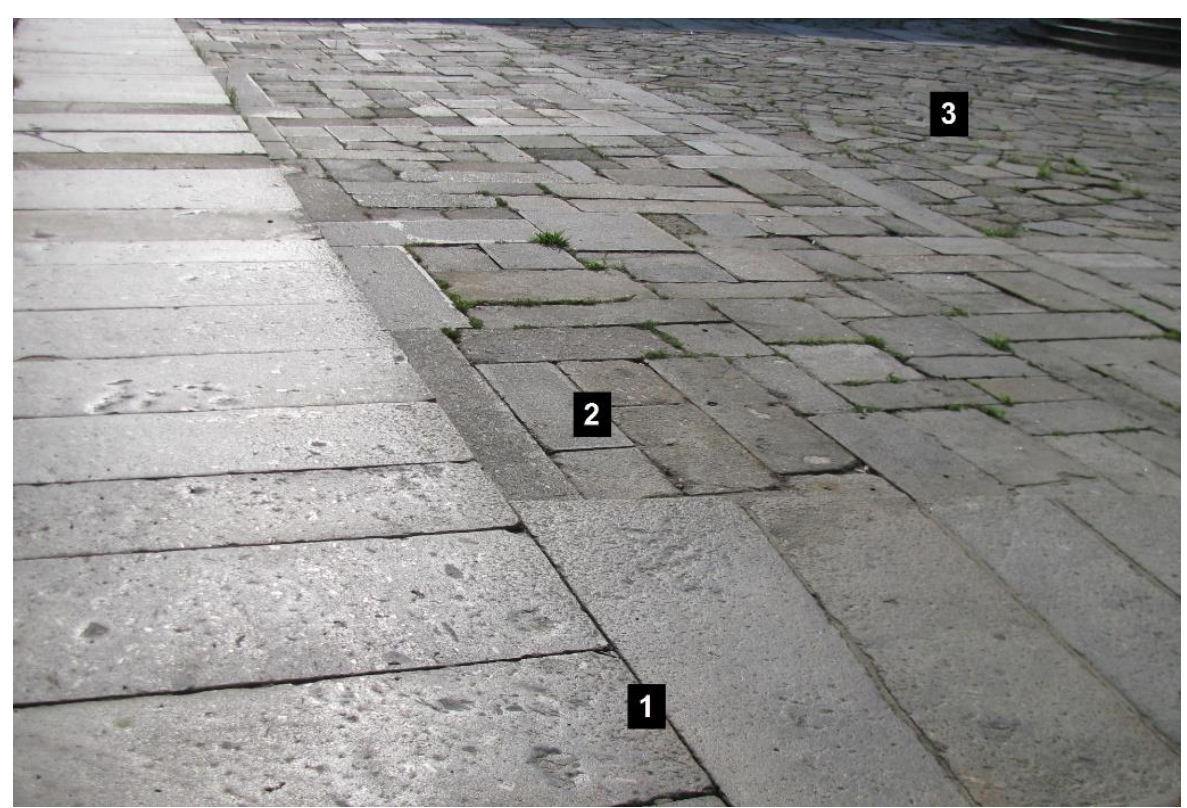

Figure 9. Illustration of referencing situation in pavements: regular disposition of geometrically regular stones in 1 , geometrically regular stones disposed in a more uneven manner in 2 and irregularly shaped stones disposed in an uneven fashion.

The image presented in Figure 9 illustrates (in a single image) different situations in pavements: in the areas marked as 1, there are regular stones disposed in a regular pattern and, hence, locating a stone or a feature within a stone will be straight forward (as in the example of Figure 8). In the area marked as 2, the individual stones still show a regular geometrical pattern but their disposition is irregular and it will harder to locate a given FGI (whether a stone or a feature within a stone). The areas marked as 3 constitute the worst scenario for FGI location as the individual stones and its disposition are irregular. Steps on traditional stairs will be also an example of regular pattern of regular stones but some extended stairs (several stones by step) and specially rounded versions of stairs will make location more difficult.

Geocaching activities (as discussed, e.g., in (Lo, 2010) can be a fun, hence motivating, way to turn the tables on this question of locating geological features on the built environment and search for creative procedures for location with the added (motivating) challenge of not being solved just by GPS coordinates. Perhaps there might be here an opportunity for promoting research in referencing systems.

\section{FINAL CONSIDERATIONS}

As has been shown in the previous sections, the built heritage present diverse opportunities for Earth Sciences teaching (at several levels of formal education, including post-graduate studies, as well as in more informal contexts including tourist activities) concerning what we referred as feature of geological interest, or FGI for short, considered here in a very wide sense that includes characteristics of geological materials that can be recognized with the naked eye and analogues of geological process on the natural environment such as crystalline neoformations, erosion figures and illustrations of the relations between substrate and biological colonization. However, this approach requires some care in terms of teaching in relation to the occurrence of geological materials outside their original geological context (as this will be extremely censored observations) and, in the case of analogies, regarding the differences between the genetic processes in the natural and built environment.

These FGI can be integrated in an information system referred here as GeoloGIS-BH (BH-built heritage). In terms of information organization, two perspectives were considered that might be of interest for different target audiences. In one of them, the GeoloGIS-BH is seen as a collection of FGIs located in built heritage occurrences. This will suitable for Earth Sciences teaching (and might also appeal to students of other sciences). In the other perspective presented above, more oriented to humanities teaching, the FGIs are components of built heritage elements and their interest will be related to their historical and architectural information content, i.e., whether they give information in historical issues and architectural issues such as the selection among local materials or the importation of non local materials due to aesthetic and functional reasons.

Besides the questions concerning the implementation as software of this system (not considered here), the main conceptual issue regarding the GeoloGIS-BH will be the findability (spatial location) of a given FGI which will depend on its visual contrast resulting of color and texture in relation to the surrounding areas and the size of the 
FGI in relation to the built heritage element as well as on the geometrical regularity of the built element where the FGI is found. The question of findability will be, in general, more relevant for the first perspective referred above, as in the second the discussion of geological features will be at a coarser scale, but in the case of a finer detailed FGI (e.g. for discussing materials provenance), the question of findability might rise again.

In this way, geological concepts can be used for the promotion and valuing of the built heritage through roadmaps showing occurrences of certain features or as part of information for a given monument. These perspectives might even give a contribution for the justification of conservation procedures, i.e. the conservation of a given built heritage element for showing a rare FGI, either locally or even globally.

\section{ACKNOWLEDGMENTS}

This work is included in the activities of the project Lab2PT - Landscapes, Heritage and Territory laboratory AUR/04509, which has financial support of the Portuguese Fundação para a Ciência e a Tecnologia through national funds and when applicable of the FEDER co-financing, in the aim of the new partnership agreement PT2020 and COMPETE2020 - POCI 010145 FEDER 007528.

The idea of the built environment as a illustrative tool for geological features benefited from field work with Narciso Miranda (of the portuguese LNEG) and with Graciete Dias, M. A. Sequerira Braga, and (also several times afterwards) with Eduardo Pires de Oliveira (the last three from the University of Minho) at the beginning (in the last century) of the research work of the older author (C. Alves).

Some points of this paper in terms of referencing of features on the built environment benefited of previous discussions with Arlindo Begonha of the Engineering School of the University of Porto.

\section{REFERENCES}

Alves, C. (2013a). Geochemistry of the built environment: Alteration products of stony materials. In SanjurjoSánchez, J. ed., Advances in Geochemistry Research, pp. 27-58. New York: Nova Science Publishers.

Alves, C. (2013b). Scanning Electron Microscopy Studies of Neoformations on Stony Materials of Modern Building Works. Microscopy and Microanalysis, 19(5), pp. 1241-1247. http://doi.org/10.1017/S1431927613012701

Alves, C. and Sanjurjo-Sánchez, J. (2015). Conservation of stony materials in the built environment. Environmental Chemistry Letters, 13(4), pp. 413-430. http://doi.org/10.1007/s10311-015-0526-2

Alves, C., Ribeiro, V., Pinto, C. and Pereira, P. (2016). Sigeolog-pc: A informação geológica na valorização do património construído. Proc. XI Jornadas Internacionais "Grandes Problemáticas do Espaço Europeu", Porto. In Portuguese.

Balestro, G., Cassulo, R., Fioraso, G., Nicolò, G., Rolfo, F., Bonansea, E., Cadoppi, P., Castelli, D., Ferrando, S., Festa, A., Groppo, C., Morelli, M., Mortara, G. and Mosca, P. (2015). IT applications for sharing geoheritage information: The example of the geological and geomorphological trail in the Monviso massif (NW Italy). Rendiconti Online Societa Geologica Italiana, 34, pp. 85-88.

Balestro, G., Cassulo, R., Festa, A., Fioraso, G., Giardino, M., Nicolò, G. and Perotti, L. (2016). 3D Geological visualizations of geoheritage information in the Monviso Massif (Western Alps). Rendiconti Online Della Società Geologica Italiana, 39, pp. 81-84. http://doi.org/10.3301/ROL.2016.52

Cunha, M., Pinto, C., Pereira, P., Ribeiro, V. and Alves, C. (2016). O SIGeolog como ferramenta para a computação do ambiente geológico. APEIRON, 7, pp. 105-124. In Portuguese.

Hoerig, K.A., Welch, J.R., Ferguson, T.J. and Soto, G. (2015). Expanding Toolkits for Heritage Perpetuation: The Western Apache Ethnography and Geographic Information Science Research Experience for Undergraduates. International Journal of Applied Geospatial Research, 6(1), pp. 59-75. http://doi.org/10.4018/ijagr.2015010104

Liu, Z. and He, D. (1998). Special speleothems in cement-grouting tunnels and their implications of the atmospheric CO 2 sink. Environmental Geology, 35(4), pp. 258-262. http://doi.org/10.1007/s002540050312

Lo, B. (2010). GPS and geocaching in education. Eugene, Or: International Society for Technology in Education.

Morville, P. (2005). Ambient findability (1st ed). Beijing; Sebastopol, CA: O’Reilly.

Nickel, E.H. (1995). The definition of a mineral. The Canadian Mineralogist, 33(3), pp. 689-690.

Pereira, D. and Marker, B. (2016). The Value of Original Natural Stone in the Context of Architectural Heritage. Geosciences, 6(1), 13. http://doi.org/10.3390/geosciences6010013

Perez-Monserrat, E., Varas-Muriel, M., Alvarez De Buergo, M. and Fort, R. (2016). Black Layers of Decay and Color Patterns on Heritage Limestone as Markers of Environmental Change. Geosciences, 6(1), 4. http://doi.org/10.3390/geosciences6010004

Sanjurjo-Sánchez, J. (2016). An Overview of the Use of Absolute Dating Techniques in Ancient Construction Materials. Geosciences, 6(2), 22. http://doi.org/10.3390/geosciences6020022 
Sanjurjo Sánchez, J., Alves, C.A.S., Vidal Romaní, J.R. and Fernández Mosquera, D. (2009). Origin of Gypsumrich Coatings on Historic Buildings. Water, Air, and Soil Pollution, 204(1-4), pp. 53-68. http:/ /doi.org/10.1007/s11270-009-0025-9

Williams, D. B. (2009). Stories in stone: travels through urban geology. Nova Iorque: Walker \& Co.

Williams, D. B. (2012). Cairns: messengers in stone. Seattle: Mountaineer Books. 